\title{
Krill (Euphausia superba) distribution contracts southward during rapid regional warming
}

\author{
Angus Atkinson*\$1 and Simeon L. Hill*\$2,
}

Evgeny A. Pakhomov ${ }^{3,4,5}$, Volker Siegel $^{6}$, Christian S. Reiss ${ }^{7}$, Valerie J. Loeb ${ }^{8}$, Deborah K. Steinberg ${ }^{9}$, Katrin Schmidt ${ }^{10}$, Geraint A. Tarling ${ }^{2}$, Laura Gerrish ${ }^{2}$, Sévrine F. Sailley ${ }^{1}$

\section{*Corresponding author}

${ }^{\$}$ These joint first authors contributed equally to this work

${ }^{1}$ Plymouth Marine Laboratory, Prospect Place, The Hoe, Plymouth PL1 3DH, UK

${ }^{2}$ British Antarctic Survey, High Cross, Madingley Rd, Cambridge CB3 OET, UK

${ }^{3}$ Department of Earth, Ocean \& Atmospheric Sciences (EOAS), University of British Columbia, Vancouver, BC, V6T 1Z4, Canada

${ }^{4}$ Institute for the Oceans and Fisheries, University of British Columbia, 2202 Main Mall, Vancouver, BC V6T 1 Z4 Canada

${ }^{5}$ Hakai Institute, PO Box 309, Heriot Bay, BC V0P 1 H0 Canada

${ }^{6}$ Thuenen Institute of Sea Fisheries, Herwigstr. 31, 27572 Bremerhaven, Germany

${ }^{7}$ Antarctic Ecosystem Research Division, South West Fisheries Science Centre, NOAA Fisheries, 8901 La Jolla Shores Dr RM333, La Jolla CA 92037, USA

${ }^{8}$ Moss Landing Marine Laboratories, 8272 Moss Landing Road, Moss Landing, CA95039, USA

${ }^{9}$ Virginia Institute of Marine Science, College of William \& Mary, Gloucester Point, VA 23062, USA

${ }^{10}$ School of Geography, Earth and Environmental Sciences, University of Plymouth, Drake Circus, Plymouth, UK

Published in Nature Climate Change, February 2019, doi:

$10.1038 / \mathrm{s} 41558-018-0370-\mathrm{z}$

Please use this link to read a view-only version of this paper:

https://rdcu.be/bhO6k 
High latitude ecosystems are among the fastest warming on the planet ${ }^{1}$. Polar species may be sensitive to warming and ice loss, but data are scarce and evidence is conflicting $^{2-4}$. Here we show that, within their main population centre in the southwest Atlantic sector, the distribution of Euphausia superba (hereafter "krill") has contracted southward over the last $\mathbf{9 0}$ years. Near their northern limit, numerical densities have declined sharply and the population has become more concentrated towards the Antarctic shelves. A concomitant increase in mean body length reflects reduced recruitment of juvenile krill. We found evidence for environmental controls on recruitment, including reduced density of juveniles following positive anomalies of the Southern Annular Mode (SAM). Such anomalies are associated with warm, windy and cloudy weather and reduced sea ice, all of which may hinder egg production and survival of larval krill 5 . However, total post-larval density has declined less steeply than the density of recruits, suggesting that survival rates of older krill have increased. The changing distribution is already perturbing the krill-centred food web ${ }^{6}$ and may affect biogeochemical cycling ${ }^{7,8}$. Rapid climate change, with associated non-linear adjustments in the roles of keystone species, poses challenges for the management of valuable polar ecosystems ${ }^{3}$.

The pelagic food webs at both poles comprise iconic species, have important biogeochemical functions ${ }^{1}$ and are commercially exploited, prompting concern over how they will respond to future climate change $\mathrm{e}^{2,3}$. At the foundation of these food webs are large, lipid-rich zooplankton species (e.g. euphausiids, copepods and amphipods), which may be particularly sensitive to warming, given their narrow temperature tolerance and ice-associated life cycles ${ }^{1-3,9}$. Poleward shifts in species' distributions are a major response to climatic warming ${ }^{10}$. These shifts have been observed at both poles but they are highly variable between species, since other compensation mechanisms are possible ${ }^{3,4,10}$. Projections are particularly uncertain at the poles because of the scarcity of long-term, large scale data on past changes ${ }^{2,4}$.

With its central role in the food web, Antarctic krill is one of the few polar species with spatially extensive sampling that spans the last 90 years ${ }^{11}$. The SW Atlantic sector $\left(20^{\circ}-80^{\circ} \mathrm{W}\right)$, which holds $>50 \%$ of the circumpolar krill stock ${ }^{12}$, has also warmed rapidly over this time ${ }^{13}$. This provides a rare opportunity to understand how a cold water stenotherm responds to rapid environmental change. Within the multinational KRILLBASE project (see Methods) we compiled all available krill net catch data spanning 1926-2016 into two large databases: one containing their numerical density (numbers of post-larval krill $\mathrm{m}^{-2}$; hereafter density), the other including length frequency, sex and maturity stage data.

During the 1920s and 1930s the highest krill densities were centred in the northern part of the southwest Atlantic sector (Fig. 1a). Since then this distribution has contracted southward and became centred more strongly over Antarctic continental shelves. Most of this contraction 
seems to have occurred since the 1970 s, prior to which high densities were maintained in the South Georgia area. The overall southward contraction across 90 years was $\sim 440 \mathrm{~km}$, manifested as a major decrease in mean density in the north and a modest decrease in the south (Fig. 1a).

The data available for the SW Atlantic sector since the mid-1970s, including nearcontinuous krill time series and multiple indices of environmental variability, are amenable to further analysis using mixed models (Table 1) to detect systematic change over time. In addition to standardisation for net type, sampling depth, time of day and time of year, our analysis accounted for the effects of uneven data coverage and known covariates of krill abundance including latitude and bathymetry ${ }^{12}$. It also ameliorated the effects of variance inhomogeneity and temporal autocorrelation, and used de-trending to avoid spurious correlation (see Methods). The data analysed in each model included up to 12 spatio-temporal averages per austral summer season (referred to as "year" in the figures). Figs 1b, 2 and 3 illustrate these statistically robust results with simpler models fitted to annual averages. The mixed models show a strongly negative time trend in krill density north of $60^{\circ} \mathrm{S}$ and a weaker trend further south (Table 1, see Fig. 1b). Indeed, density trends at the highest latitudes sampled (south of $65^{\circ} \mathrm{S}$ ) were neutral or positive (Fig. 2a). The overall trend was apparent in independent subsets of the data based on net size (Supplementary Table 1), and the stronger negative trends north of $60^{\circ} \mathrm{S}$ are seen in encounter probability data (Fig. S3)

There was also a long-term, spatially coherent trend in the mean krill length dataset (Fig. 2b, Fig. 3a). Individuals in the current krill population are on average $6 \mathrm{~mm}$ longer than those in the 1970 s, equating to a roughly $75 \%$ increase in their mean body mass. This is opposite in direction to the more common finding of reduced body size of species in response to warming ${ }^{14}$, and instead reflects changes in demographic structure of the krill population. Given the counteracting effects of decreasing numbers and increasing individual mass, the substantial (70\%) decrease in numerical density over 20 years spanning the 1976-1996 and 1996-2016 eras equates to a smaller (59\%) decline in biomass density. In addition to the opposing longterm trends, length also varied with density on an inter-annual scale, such that low density years were characterised by a higher than average mean length (Fig. 3b, Table 1).

Previous studies have identified various potential environmental drivers of krill population dynamics ${ }^{5,11,15-18}$. The clearest environmental covariate of krill density that we found was the Southern Annular Mode (SAM) (Fig. 3c), which is also related to mean length and recruit density (Fig. 3d, Table 1). The SAM is an index of hemisphere-scale atmospheric circulation which might influence krill population dynamics by affecting the recruitment of small $(\leq 30 \mathrm{~mm})$ krill to the population each year, ${ }^{3,5}$. Summers of strong recruitment tend to follow periods with negative SAM anomalies. Sequential years of poor recruitment are periodically boosted by a year or two of good recruitment where many small krill swell the numbers but depress the 
average size $\mathrm{e}^{5,15,16}$. This explains the negative relationship between krill density and mean length (Table 1) illustrated in Fig. 3b.

Over the last 40 years, recruitment has declined sharply (Fig. 2c, Fig. S1a, Table 1) and indeed significantly more abruptly than the decline in total krill density (Fig. S1b). This is coincident with an ongoing trend towards increasingly positive SAM anomalies (Fig. 3c) which indicate the southward influence of storm tracks across the SW Atlantic sector, low pressure, warmer, cloudier and windier conditions and reduced sea ice ${ }^{5,18-20}$. Such conditions negatively affect adult feeding, impacting early spawning in spring, early larvae in summer and later larval stages which may need early-forming, complex and well illuminated marginal sea ice to promote survival ${ }^{17}$. The exact mechanisms are likely to vary with latitude. For example, increasing summer temperatures present a physiological challenge for this stenothermal species at their northern limit ${ }^{9}$, where a strong link between climate, temperature anomalies and krill recruit biomass has also been identified ${ }^{18}$. Further south, near the tip of the Antarctic Peninsula, the biomass and quality of phytoplankton food have also declined ${ }^{21}$. In contrast, at the southern part of the Western Antarctic Peninsula, the loss of permanent sea ice and increases in phytoplankton biomass ${ }^{20}$ are associated with a more stable or even increasing krill density ${ }^{5,16}$ (Fig. 2a).

Suggestions that krill density has declined within the southwest Atlantic sector ${ }^{11,15}$ have major ramifications for fisheries management and are the subject of some debate ${ }^{3,16,22}$. Indeed a recent paper $^{23}$, which reports an analysis of a subset of our data, argues that previous evidence of a decline ${ }^{11}$ "is a consequence of not considering interactions between krill density and unbalanced sampling in time and space in the data, and not accounting for the different net-types used." We agree with these authors ${ }^{23}$ that analyses of this complex database require care. Our study considered each of the issues they identify, which suggests that the contrast between their ${ }^{23}$ conclusions and ours reflects other differences in approach. First, we excluded negatively biased records resulting from sampling in winter or solely in deeper strata, while they did not. Second, we followed established practice $5,11,15,18,26$ in using spatially resolved annual mean densities as a basic unit, logging these as appropriate. Conversely, they ${ }^{23} \log$ transformed at the level of individual records, down-weighting the influence of the high swarm densities which are a critical feature of krill distribution ${ }^{12}$. This substantially underestimates the mean and variance in krill density (their ${ }^{23}$ Figs 1,3 ) compared to previous studies $^{12}$. Third, while we used statistical hypothesis testing to assess the probability that the detected decline is a false trend (type I error, indicated by our P values), they did not quantify the probability of failing to find a real trend (type II error). Overall, we consider that our findings provide a more robust picture of the spatial pattern of krill density time trends within the SW Atlantic sector. 
Notwithstanding differences in the way that krill density data may be screened and analysed, the length frequency database provides independent evidence that krill dynamics have changed fundamentally. The coherent inter-relationships among krill density, mean length and SAM also provide a plausible driving mechanism. The spatial coherence in these changes supports the concept of a large and connected marine ecosystem linked by advection ${ }^{18,24}$. Reduced birth weights of fur seals at South Georgia ${ }^{6}$ suggest major changes in the krill-based food web in the northern part of krill's range. Likewise, in the far south, observations of more stable krill densities and recruitment ${ }^{5,16}$ align with our conclusion that the distribution of krill is contracting southward.

Polar food webs are structured both by top-down and bottom-up effects, but their relative roles are debated ${ }^{1,2,22}$. Several strands of evidence point to climatic change as a major driver of krill dynamics in this sector. First, in the Indian sector of the Southern Ocean, where sea ice and temperature have been more stable over the last 50 years $^{19}$, there was no evidence for the basin-scale decline in krill stocks that is observed in the rapidly warming SW Atlantic sector $^{11}$. Second, within the SW Atlantic sector the gradation from a steep decline in density at lower latitudes towards more stable densities in the south concurs with observed and projected poleward distribution shifts under warming ${ }^{2,3,10}$. These changes cannot be explained by any known changes in the suite of krill predators. The relationships between de-trended SAM and krill population variables are both significant and coherent but other drivers and time-lags, unresolvable at our scale of analysis, will also influence krill dynamics throughout the sequence from spawning, through larval stages to the $>5$-year post-larval life.

While the weight of evidence above suggests a predominantly bottom-up control on krill that has caused a contraction in its distribution, the relative strength of top-down and bottom up factors will likely be scale-dependent. At small scales, predation can drive risk-reward trade-offs such as schooling behaviour and vertical migrations ${ }^{25}$. Over the much longer timespan of changing predator populations, the extent and sources of top-down control will vary ${ }^{1-3}$. Indeed, total density has not declined so rapidly as recruit density (Fig. S1). One possible explanation is a counteracting increase in survival of older krill, due to long-term changes in predation, intraspecific competition ${ }^{26}$ or other density-dependent factors ${ }^{18}$.

The changes in krill density, mean size and range have a series of profound implications (Fig. S2). First, because of the earth's geometry the distribution is contracting into a diminishing area, and further retreat is blocked by the continent itself. Since total abundance is a product of numerical density and area, reductions in numerical density will translate to greater reductions in total abundance ${ }^{2}$. Population genetics studies suggest fluctuations in krill population size over longer timescales ${ }^{27}$, perhaps reflecting expansions and contractions from habitat refugia during glacial and inter-glacial epochs ${ }^{28}$. The highest krill densities tend to occur in shelf habitats ${ }^{12}$ so the greater area of shelf in the south would result in an increasingly shelf-oriented population 
during warm periods. In a warmer world, a more fragmented, shelf-based distribution may restrict access to the deep water needed for spawning and limit dispersal and basin-scale connection within the Antarctic Circumpolar Current ${ }^{22,29}$. The primary production in alternative, high latitude spawning areas might increase in future, but projections suggest that these areas will become more spatially restricted ${ }^{29}$, have a shorter growing season and, over the longer term, become adversely affected by ocean acidification effects on egg hatch success ${ }^{30}$.

Such changes in krill dynamics would have major ramifications for food web linkages and biogeochemical cycling (Fig. S2). When high densities of krill extend across the SW Atlantic sector, they support a suite of predators ${ }^{3,18}$. The fecal pellets cascading from krill schools provide pulses of carbon that can dominate particle export ${ }^{7}$. Their feeding and digestion also mobilises iron from diatoms and lithogenic sediment, in turn helping to fertilise phytoplankton blooms $^{8,25}$. In a reorganised food web with a contracted distribution of larger krill over high latitude shelves, these functions will change. For example, the increased krill size might alter predator-prey interactions and allow greater swimming speeds, with the potential to migrate to cooler feeding grounds near the seabed ${ }^{25}$. This has major implications for nutrient cycles ${ }^{1,8}$, and could link krill to a different suite of predators ${ }^{25}$

Given the implications for food security and biodiversity, there is intense interest in projecting future stock sizes of krill and other high biomass species such as anchovies or sardines $^{3,18,24}$. Current management of the krill fishery sets conservative catch limits but does not yet account for trends in stock size or distribution ${ }^{22}$. Models point to an ongoing increase in positive SAM anomalies for the next 50 years ${ }^{20}$, coupled with warming and reduced ice cover. This would suggest a further contraction in krill distribution, associated with a suite of mainly adverse effects (Fig. S2). However, climate-population relationships are inherently non-linear and can change abruptly as food webs shift into new states ${ }^{2}$. For example, abrupt latitudinal changes in bathymetry may constrain readjustments of distribution in polar regions, and Fig. S1 suggests a possible increase in survival, partially compensating for the sharp decline in recruitment. Species vary greatly in the extent to which their distributions change ${ }^{10}$, these responses being modulated by genetic adaptation or via adjustments to phenology or behaviour ${ }^{3,4}$. Various projections for krill have been made ${ }^{9,16,18,29,30}$, but given the likelihood of non-linearities ${ }^{18}$, these remain uncertain. Long-term data therefore remain the lifeblood of our understanding of climate change responses and are key to the informed management of polar ecosystems. 


\section{Methods}

\section{KRILLBASE abundance database}

We have created a database, entitled "KRILLBASE-abundance ${ }^{31 ", ~ t o ~ r e s c u e ~ a n d ~}$ collate all available data from untargeted net catches across the Southern Ocean. It was compiled through "data rescue" from old notebooks, the authors' datasets, published reports and submissions by other data contributors. The full database comprises 15,194 net hauls spanning the 1926 - 2016 period and has data on the numerical density (number $\mathrm{m}^{-2}$ ) of postlarval Euphausia superba, hereafter described simply as "density". This dataset (Fig. S4) is derived from sampling stations at predetermined or randomly selected positions and excludes hauls targeted on krill swarms. It includes $\sim 50 \%$ more data than previously published versions of the database ${ }^{11,32}$. The full database is circumpolar and comprises data from 10 nations spanning 56 sampling seasons. Section 13 describes data availability.

\section{KRILLBASE length-frequency data base.}

We have compiled a separate database, entitled "KRILLBASE-length frequency", which includes length, sex and maturity-stage data for Euphausia superba. Unlike the abundance counterpart, this contains data from hauls targeted on krill schools as well as those from random or predetermined locations. This database is also circumpolar, comprising over 11,000 sampling stations over 47 seasons within the period 1926-2014 (Fig. S5). With over 1 million individual krill length measurements both from scientific and commercial nets, the length-frequency database is much larger than, and compiled independently of, the abundance database ${ }^{33}$. The full dataset comprises data from ten nations, either available in the authors' home institutes, sent directly by other contributors or transcribed from publications and reports. Section 13 describes data availability.

\section{Transformation and screening of data}

Both the density and the length-frequency databases required some screening for the current analyses. The SW Atlantic sector of interest was defined as $20^{\circ}-80^{\circ} \mathrm{W}$ and between the Antarctic Polar Front and $75^{\circ} \mathrm{S}$. We divided hauls according to "austral summer" season (for example the 1985 season encompassed all stations sampled between 1 Oct 1984 and 30 April 1985), thereby screening out winter data. Most sampling in both screened datasets was in the summer months, with $76 \%$ of hauls in the period December to February. For consistency with other work ${ }^{32}$, the density data were further screened according to the net sampling depths, removing all hauls where the upper sampling depth was $>20 \mathrm{~m}$ or the lower sampling depth was $<50 \mathrm{~m}$. The median upper and lower depths were 0 and $170 \mathrm{~m}$ 
respectively in the screened density dataset. The length frequency dataset was screened by removing all krill $<15 \mathrm{~mm}$ long, since these include larvae. Nets with large meshes provide biased estimates of size distribution, therefore we excluded data from all commercial or semicommercial trawls and scientific nets with meshes > $6 \mathrm{~mm}$ (e.g., RMT25s).

We have included both targeted and non-targeted hauls for analysis of length frequency distribution, following the recommendation ${ }^{34}$ that the priority is to sample a sufficient number of krill to be representative of the wider population, which can require combining targeted and non-targeted hauls where necessary. However to test whether this may have caused a bias in the time trends we divided the hauls into those that provided a representative sample of the whole top 100m layer and the remainder (including targeted hauls). An increase in mean krill length was seen independently in both subsets of data, supporting Fig. 2 and 3. Therefore we pooled the two data sources for subsequent analyses.

The krill-density estimates were based on a wide range of sampling net types, depth ranges and times of year, all of which can potentially bias temporal-spatial trends. We therefore applied conversion factors to each haul to standardise to a single, relatively efficient net sampling method. The chosen efficient sampling combination was a night-time haul with an $8 \mathrm{~m}^{2}$ net from 0-200 m on 1 January. The statistical method of adjusting the krill density values to this sampling method, including model coefficients and sensitivity analysis, are described is previous papers ${ }^{31,32}$.

It is important to note that this standardisation model only used nets sampled concurrently within the modern era; we could not use the $1 \mathrm{~m}$ diameter nets with release gear used during the 1920s and 1930s for the standardisation as there were no other net types fished concurrently. Therefore the absolute values of standardised krill density presented for the 1920s and 1930s (top panels of Fig. 1a) must be considered as approximate. Nevertheless, and particularly for the modern era, we believe that this data standardisation provides a more consistent view of spatial-temporal changes in krill density than the raw density data. Therefore for all analyses in the main text we used standardised densities. Unstandardised data as well as subsets of the data by sampling method were analysed to assess the sensitivity of our results to sampling method and standardisation. These analyses indicate that the results are broadly coherent across the different methods (see Supplementary Table 1).

\section{Environmental data}

The KRILLBASE-abundance database includes data on depth at each sampling station, based on a mean value for a $10 \mathrm{~km}$ radius buffer around each station from the GEBCO bathymetry ${ }^{31}$. These values provide a basis for characterising whether the station was over the shelf $(\leq 1000 \mathrm{~m})$ or in oceanic waters $(>1000 \mathrm{~m})$. We tested krill indices against a 
variety of physical variables (see Methods section 9). These included first, the Southern Annular Mode anomalies, obtained from the British Antarctic Survey, Natural Environment Research Council ${ }^{35}$ (http://www.nerc-bas.ac.uk/icd/gima/sam.html). Multivariate ENSO (MEI) values were obtained from the National Oceanic and Atmospheric Administration, Earth System Research Laboratory, Physical Sciences Division ${ }^{36}$ https://www.esrl.noaa.gov/psd/data/correlation/mei.data.

For sea-ice, median values of ice cover were obtained from two passive microwave radiometer datasets; the Microwave Scanning Radiometer-Earth Observation System (AMSRE) ${ }^{37}$ aboard the NASA's Aqua satellite and the Defense Meterological Satellite Program SSM/I http://nsidc.org/data/nsidc-0051.html. From these, the northern latitudes of $15 \%$ concentration were obtained. In addition we tested indices of fast ice timing of formation, breakout and duration from the South Orkney Islands time series ${ }^{38}$.

\section{KRILLBASE data coverage and spatial-temporal pooling}

Because KRILLBASE is a data rescue and compilation project, data from the abundance and length frequency databases were not distributed homogeneously in time and space. To counteract this we have used a suite of methods and sampling units to examine key relationships. Spatially these include division of the SW Atlantic sector $\left(20^{\circ}-80^{\circ} \mathrm{W}\right)$ data into $2.5^{\circ}$ latitudinal bands, and into shelf versus oceanic portions. This resulted in 12 spatial units defined by $2.5^{\circ}$ latitudinal band and bathymetry (shelf versus oceanic waters). Following reference ${ }^{11}$ we excluded spatial units with fewer than 50 stations or 5 sampling seasons from the spatial visualisations in Fig. 1a and Fig. S5. Temporally we have used austral "year" (i.e. from October of the previous year to April in the given year) as the basic unit of sampling, based on the great variability in krill density and mean length observed between successive years due to inter-annual variation in recruitment ${ }^{15,18,26,39-41}$. Our analyses (e.g. Figs. 1b, 2, and Supplementary Fig. $\mathbf{3}$ and $\mathbf{5 b}$ ) provide time trends and relationships that were broadly coherent right across the SW Atlantic sector. For this reason, our illustration of key relationships in Fig. 3 is at this whole-sector scale, supported by the mixed models that include the finer subdivisions described above.

\section{Visualisation of the contraction in distribution}

To provide a visualisation of the changes in distribution revealed statistically by mixed model no.1 (Table 1) we have divided the sampling into 3 periods based on sequential years of sampling (namely the 1920s and 1930s, then further dividing the modern era, 1976-2016, into two roughly equal time spans). Sample coverage in each period is provided in Fig. S4. We further restricted the analysis to an area sampled adequately in all three eras. This was defined by a polygon (red line in Fig. S4) including a sub-region that was sampled consistently 
but in lower density (hatched area in Fig. S4). To visualise changes in the hotspots of krill density (Fig. 1a) we used the kernel density tool in ArcGIS to grid the density sample points from each sampling era. Kernel density estimation is a non-parametric smoothing interpolation that calculates the density of points in a specified distance around each feature. We used this approach because it is not prone to edge effects and, across the domain of each map, could objectively identify hotspot areas of elevated density.

\section{Calculation of population central latitude in each era}

We calculated the population central latitude in each era based on the stratification in to six $2.5^{\circ}$ latitudinal bands described in section 5 above, and illustrated in Fig. 1a. Population central latitude is the sum of the products of stratum mean density and stratum mid latitude, divided by the sum of stratum mean densities. While the substantial southwards contraction of range within the modern era (Fig. 1a) is supported independently by both shelf and oceanic krill sampling stations, we should stress that this analysis, plus the spatial depictions in Fig. 1a are for illustrative purposes only. Statistical evidence for a range contraction is provided by the spatio-temporal analysis within mixed model no. 1 in Table 1 (see also section 10 below).

\section{Calculation of recruit density}

Recruit density is defined here as the mean density of post-larval krill $\leq 30 \mathrm{~mm}$ in length ${ }^{40}$. This is an estimation of the density of post-larval krill that are likely to be about 1 year old within the October to April timeframe of each year's observations ${ }^{40}$. Density of new recruits in each season was thus calculated as a product of proportional recruitment (the fraction of the krill measured that were $15-30 \mathrm{~mm}$ in length) and mean standardised post-larval krill density.

\section{Preliminary analysis of relationships with environmental variables.}

In a series of preliminary analyses we examined inter-annual variability in a series of response variables, namely total post-larval krill density, recruit density and mean length at a range of spatial and temporal scales. The candidate explanatory variables included winter sea-ice cover (indexed by ice formation, duration, and breakout times from the South Orkneys fast ice datase ${ }^{38}$ ) plus satellite-derived monthly northerly extent of $15 \%$ ice averaged within a series of $10^{\circ}$ longitude bands. Climatic indices included SAM (Southern Annular Mode) and MEl (multivariate El Niño/Southern Oscillation) monthly data with variable lags and integration periods. The best fit Gaussian GLM (weighted by the number of krill sampling stations per year) had SAM as the explanatory variable (i.e. average of monthly SAM anomalies for the period January to September preceding the October to April season of the krill observations) . At the largest scale of our study, the best sea-ice relationship explained much less of the variance than SAM, perhaps reflecting more localised specific conditions of ice-krill 
relationships ${ }^{16,40,41}$. ENSO has also been identified as a driver of krill dynamics near the Antarctic Peninsula ${ }^{39-41}$. We found that ENSO (indexed by the MEI) related significantly to krill with very short and long lag times, but these disappeared when added to models alongside SAM, which was thus by far the clearest predictor at the whole SW Atlantic scale.

\section{Preliminary analysis of trends}

We used LOESS regression, implemented using the loess function in the R package stats $^{43}$ (span=1, degree $=1$ ) to visualise time trends in response variables: These were acrossstation averages of standardised post-larval density, length, and recruit density, grouped by season and spatial unit. The spatial units were defined by latitude $\left(2.5^{\circ}\right.$ bands) and bathymetry (shelf versus oceanic waters $>1000$ m deep) (Fig. 2). Post-larval density and recruit density were increased by a constant (half of the minimum post-larval density across all spatio-temporal units) and $\log _{10}$ transformed prior to analysis.

Encounter probability (the proportion of samples in which the subject species is present) is a common metric of species distribution. This metric (Fig. S3) corroborated our findings on numerical density (Fig. 2), namely a strong decline in the north, trending towards a more stable situation towards the south, suggestive of a contraction in the distribution. However, we chose density as the focus of our main analysis, given the highly heterogeneous distribution of krill.

\section{Linear mixed models}

The datasets used in this analysis were compiled from multiple surveys with a variety of designs, locations and sampling methods. Standardisation ${ }^{31,32}$ allows comparison of data from individual stations, but analysis of temporal patterns in such data must also ameliorate the effects of pseudoreplication and inhomogeneity of variance. Further issues include potential temporal autocorrelation and the risk of spurious correlation due to time trends in multiple variables. Our exploration of changes in krill population characteristics and their relationships with environmental variables in the modern era (1976 to 2016) addresses each of these issues. We used $\mathrm{R}^{42}$ for all statistical analyses.

To ameliorate the effects of pseudoreplication, our analysis was conducted using linear mixed models which considered spatial unit, year and the interaction between them, as random effects. We used the Ime function in the $\mathrm{R}$ package $n \mathrm{Ime}^{43}$ to fit models using restricted maximum likelihood.

We investigated the fixed effects of latitude by including a candidate variable, LAT, indicating whether the sample was north or south of $60^{\circ} \mathrm{S}$. This gave a reasonable balance of data between north and south but it was not possible to explore bathymetric contrasts in 
length and recruit density north of $60^{\circ} \mathrm{S}$ (Fig. 2). The main candidate explanatory variable was year for models 1-3 in Table 1, de-trended mean length for model 4 and de-trended SAM (average of monthly anomalies for the period January to September preceding the krill sampling season) for models 5 to 7 . We considered the most complete form of each model including fixed effects for the main candidate variable plus latitude and bathymetric bin where feasible; interactions between them; and random effects.

We arrived at the final models presented in Table 1 by using model selection to identify fixed and random effect variables from the set of candidates listed above, including interactions. Model selection also identified appropriate representations of variance as a function of the reciprocal of the number of stations (from candidate fixed, power and exponential functions), to ameliorate the effects of inhomogeneity of variance. It also identified an appropriate correlation structure (from candidate autoregressive order 1 and autoregressive moving average functions) to ameliorate the effects of temporal autocorrelation where relevant. All model selection was based on AIC, and the identification of fixed effects also considered differences between models based on likelihood ratios. The selected variance function was a power function for all models except model 2 , which used a linear function.

To avoid spurious correlations when both the response and main candidate explanatory variable included a time trend, we de-trended both variables using the relevant time trend model. The de-trended variable was the original value minus the fitted value based on fixed effects.

We used visual checks to verify that response data were approximately normally distributed and that model fits were convincing. We verified that the autocorrelation statistics in the selected models were not significantly different from zero. We also used the Levene test $\left(\mathrm{R}\right.$ package $\mathrm{car}^{44}$ ) to verify that each model was not significantly affected by heteroscedacity. Finally, we used the r.squaredGLMM function in the $\mathrm{R}$ package MuMIn ${ }^{45}$ to estimate the variance explained by the fixed and random effects in each model. In high variability datasets like ours, the variance explained by linear models featuring one or two explanatory variables is typically low, particularly when variables are detrended. The main statistic for detecting relationships is the $P$ value, which indicates whether the linear model slope is significantly different from zero.

To assess the difference in time trends between recruit density and total post-larval density (Fig. S1) we restricted the data set to years and spatial units for which both types of density estimate were available. We constructed a linear mixed model with density as the response variable, year as the main explanatory variable and an additional explanatory variable indicating the type of density estimate (recruit or total post-larval). A significant interaction between explanatory variables indicates a significant difference in slope. 
We explored the sensitivity of the time trend in krill density to data selection and processing by fitting model 1 to alternative versions of the dataset (Supplementary Table 1). Specifically, we used (i) unstandardised krill density data, (ii) data only from nets with nominal mouth areas $>3 m^{2}$, and (iii) data only from nets with nominal mouth areas $\leq 3 m^{2}$. All models identified the negative time trend, but the models fitted to smaller datasets filtered by net size did not identify a latitudinal difference in trend. As krill aggregate in dense swarms with few krill between, the probability of mean density being zero increases at low sample sizes. Consequently, when means based on $<15$ stations are included, there is a weak relationship between number of stations and mean density. To confirm that the variance function ameliorates this effect, we also fitted all models with density or recruit density as a response variable to restricted datasets which excluded averages based on $<15$ stations. In all cases the main fixed effects remained significant.

\section{Calculated decline in density and biomass during the modern sampling era} The average separation between sampling in the first and second halves (1976-1995 and 1996-2016) of the modern era is 20.5 years. We thus used the time trends in Table 1 to determine respective average changes in density and length over 20.5 years. We used the unweighted mean of the north and south slopes for density, so the estimated change is analogous to that expected for a transect with equal length on either side of latitude $60^{\circ} \mathrm{S}$. Mean lengths were converted to individual dry mass using Scotia Sea-specific length-mass regressions ${ }^{46}$ and biomass density was calculated as the product of individual dry mass and numerical density. These revealed the $70 \%$ decline in density and $59 \%$ decline in biomass density quoted in the text.

\section{Data availability}

We have made the KRILLBASE-abundance database publically available from the Polar Data Centre at the British Antarctic Survey http://doi.org/brg8 with supporting metadata ${ }^{31}$ which should be consulted for further details. Likewise KRILLBASE-length frequency data are also available on request to the Polar Data Centre, with supporting metadata. 


\section{References}

1 Smetacek, V. \& Nicol, S. Polar ocean ecosystems in a changing world. Nature 437, 362-368 (2005).

2 McBride M.M., Dalpadado, P., Drinkwater, K.F., Godø, O.R., Hobday, A.J., Hollowed, A.B., Kristiansen, T., Murphy, E.J., Ressler, P.H., Subbey, S., Hofmann, E.E. \& Loeng, H. Krill, climate, and contrasting future scenarios for Arctic and Antarctic fisheries. ICES J. Mar. Sci. 71, 1934-1955 (2014).

3 Constable, A.J. et al. Climate change and Southern Ocean ecosystems I: how changes in physical habitats directly affect marine biota. Glob. Change Biol. 20, 3004-3025 (2014).

4 Tarling, G.A., Ward, P. \& Thorpe, S.E. Spatial distributions of Southern Ocean mesozooplankton communities have been resilient to long-term surface warming. Glob. Change Biol. doi: 10.11111/gcb.13834. (2017).

5 Steinberg, D.K., Ruck, K.E., Gleiber, M.R., Garzio, L.M, Cope J.S., Bernard, K.S., Stammerjohn, S.E., Schofield, O.M.E., Quetin, L.B. \& Ross, R.M. Long term (1993-2013) changes in macrozooplankton off the Western Antarctic Peninsula. Deep-Sea Res. I 101, 54-70 (2015)

6 Forcada, J. \& Hoffman J.I. Climate change selects for heterozygosity in a declining fur seal population. Nature 511, 462-465 (2014).

7 Gleiber, M.R., Steinberg, D.K. \& Ducklow, H.W. Time series of vertical flux of zooplankton fecal pellets on the continental shelf of the western Antarctic Peninsula. Mar. Ecol. Prog. Ser. 471, 23-36 (2012).

8 Schmidt, K, Schlosser, C., Atkinson, A., Fielding, S., Venables, H.J., Waluda, C.M. \& Achterberg, E.P. Zooplankton gut passage mobilises lithogenic iron for ocean productivity. Curr. Biol. 26, 2667-2673 (2016).

9 Wiedenmann, J., Cresswell, K. \& Mangel, M. 2008. Temperature- dependent growth of Antarctic krill: predictions for a changing climate from a cohort model. Mar. Ecol. Prog. Ser. 358, 191-202 (2008).

10 Chen I.-C., Hill, J.K., Ohlemüller, R., Roy, D.B. \& Thomas, C.D. Rapid range shifts of species associated with high levels of climate warming. Science 333, 1024-1026 (2011).

11. Atkinson, A., Siegel, V., Pakhomov, E.A, \& Rothery, P. Long-term decline in krill stock and increase in salps within the Southern Ocean. Nature 432, 100-103 (2004).

12 Siegel, V. \& Watkins, J.L. Distribution, biomass and demography of Antarctic krill, Euphausia superba. In Siegel V (ed) Biology and ecology of Antarctic krill. Advances in Polar Ecology. Springer, Basel, pp 21-100 (2016).

13 Whitehouse, M.J., Meredith, M.P., Rothery, P., Atkinson, A., Ward, P. \& Korb, R.E. Rapid warming of the ocean around South Georgia, Southern Ocean, during the $20^{\text {th }}$ century: forcings, characteristics and implications for lower trophic levels. Deep-Sea Res I 55, 1218-1228 (2008). 
14 Daufresne, M., Lengfellner, K., \& Somner, U. Global warming benefits the small in aquatic ecosystems. Proc. Natl. Acad. Sci. 106, 2788-12793 (2009).

15 Loeb, V. et al. Effects of sea-ice extent and krill or salp dominance on the Antarctic food web. Nature 387, 897-900 (1997).

16 Quetin, L.B., Ross, R.M., Fritsen, C.H. \& Vernet, M. Ecological responses of Antarctic krill to environmental variability: can we predict the future? Antarctic Sci. 19, 253-266 (2007).

17 Meyer, B. et al. The winter pack-ice zone provides a sheltered but food-poor habitat for larval Antarctic krill. Nature Ecology and Evolution https://doi.org/10.1038/s41559-017-0368-3 (2017).

18 Murphy, E.J., Trathan, P.N., Watkins, J.L., Reid, K., Meredith, M.P., Forcada, J., Thorpe, S.E., Johnston, N.M., Rothery, P. Climatically driven fluctuations in Southern Ocean ecosystems. Proc Roy Soc B 274, 3057-3067 (2007).

19 Bintanja, R, van Oldenborgh, G.J., Drifhout, S.S., Wouters, B. \& Katsman, C. A. Important role for ocean warming and increased ice-shelf melt in Antarctic sea ice expansion. Nature Geoscience 6, 376-379 (2013)

20 Gillett, N.P. \& Fyfe, J.C. Annular mode changes in the CMIP5 simulations. Geophys. Res. Letts. 40, 1189-1193 (2013).

21 Montes-Hugo, M., Doney, S.C., Ducklow, H.W., Fraser, W., Martinson, D., Stammerjohn, S.E., \& Schofield, O. Recent changes in phytoplankton communities associated with rapid regional climate change along the western Antarctic Peninsula. Science 323, 1470-1473 (2009).

22 Nicol, S. Foster, J. \& Kawaguchi S. The fishery for Antarctic krill - recent developments. Fish Fisheries 13, 30-40 (2012).

23 Cox, M.J., Candy, S., de la Mare, W.K., Nicol, S., Kawaguchi, S., \& Gales, N. No evidence for a decline in the density of Antarctic krill Euphausia superba Dana, 1850, in the Southwest Atlantic sector between 1976 and 2016. J. Crust. Biol. (2018) doi:10.1093/jcbiol/ruy072.

24 Hofmann, E.E. \& Murphy, E.J. Advection, krill, and Antarctic marine ecosystems. Ant. Sci. $16,487-499(2004)$

25 Schmidt, K., et al. Seabed foraging by Antarctic krill: implications for stock assessment, bentho-pelagic coupling, and the vertical transfer of iron. Limnol. Oceanogr. 56, 1411-1428. (2011).

26 Ryabov, A.B., de Roos, A.M., Meyer, B., Kawaguchi, S. \& Blasius, B. Competition-induced starvation drives large-scale population cycles in Antarctic krill. Nature Ecol. Evol. 1, 0177 doi:10.1038/s41559-017-0177(2017).

27. Goodall-Copestake, W.P., Pérez-Espona, S., Clark, M.S., Murphy, E.J., Seear P.J., Tarling, G.A. Swarms of diversity at the gene cox1 in Antarctic krill. Heredity 104, 513-518 (2010).

28 Spiridonov, V.A. A scenario of the late-Pleistiocene-Holocene changes in the distributional range of Antarctic krill (Euphausia superba). Mar. Ecol. 17, 519-541 (1996).

29 Piñones, A. \& Fedorov, A.V. Projected changes of Antarctic krill habitat by the end of the $21^{\text {st }}$ century. Geophys. Res. Letts. 43, 8580-8589 (2016). 
30 Kawaguchi, S., Ishida, A., King, R., Raymond, B., Waller, N., Constable, A., Nicol, S., Wakita, M. \& Ishimatsu, A. Risk maps for Antarctic krill under projected Southern Ocean acidification. Nature Clim. Change 3, 843-847 (2013).

\section{Additional Method References}

31. Atkinson A. et al. KRILLBASE: a circumpolar database of Antarctic krill and salp numerical densities, 1926-2016. Earth Syst. Sci. Data 9, 1-18 (2017).

32. Atkinson, A., Siegel, V., Pakhomov, E.A., Rothery, P., Loeb, V., Ross, R.M., Quetin, L.B., Fretwell, P., Schmidt, K., Tarling, G.A., Murphy, E.J. \& Fleming A. Oceanic circumpolar habitats of Antarctic krill. Mar. Ecol. Prog. Ser. 362, 1-23 (2008).

33. Tarling, G.A., Hill, S., Peat, H., Fielding, S., Reiss, C. \& Atkinson A. Growth and shrinkage in Antarctic krill Euphausia superba is sex-dependent. Mar Ecol. Prog. Ser. 547, 61-78 (2016).

34. Watkins, J. Sampling krill. In: Everson, E. (ed). Krill biology, ecology and fisheries. Blackwell Science, Oxford, pp 8-39. (2000)

35. Marshall, G. J. Trends in the Southern Annular Mode from observations and re-analyses. J. Clim. 16, 4134-4143 (2003).

36. Wolter, K. \& Timlin, M. S. El Niño/Southern Oscillation behaviour since 1871 as diagnosed in an extended multivariate ENSO index (MEI.ext). Intl. J. Clim.

31, 1074-1087 (2011).

37. Spreen, G.,Kaleschke,L. \&Heygster, G. Sea ice remote sensing using AMSR-E 89-GHz channels. J. Geophys Res-Oceans C02S03 (2008).

38. Murphy, E.J., Clarke, A., Abram, N.J. \& Turner, J. Variability in sea ice in the northern Weddell Sea during the $20^{\text {th }}$ century. J. Geophys. Res.-Oceans 119, 4549-4572. (2014) 
39. Ross, R.M., Quetin, L.B., Newberger, T., Shaw, C.T., Jones, J.L. Oakes, S.A. \& Moore, K.J. Trends, cycles, interannual variability for three species west of the Antarctic Peninsula, 1993-2008, Mar. Ecol. Prog. Ser. 515, 11-32 (2014).

40. Saba G.K. et al. Winter and spring controls on the summer food web of the coastal West Antarctic Peninsula. Nature Communications 5, 4318 doi 10.1038/ncomms5318 (2014).

41. Loeb, V. \& Santora, J.A. Climate variability and spatiotemporal dynamics of five Southern Ocean krill species. Prog. Oceanogr. 134, 93-122 (2015).

42. R Core Team. R: a language and environment for statistical computing. $R$ Foundation for statistical computing, Vienn. ISBN 3-900051-07-0. http://www.R-project.org/. (2013).

43. Pinheiro J, Bates D, DebRoy S, Sarkar D and R Core Team. nlme: Linear and Nonlinear Mixed Effects Models. R package version 3.1-131, https://CRAN.R-project.org/package=nlme (2017).

44. Fox J. \& Weisberg, S. An "R" Companion to applied regression. Second Edition. Thousand Oaks, California. http://socserv.socsci.mcmaster.ca/jfox/Books/Companion (2011).

45. Barton K. MuMIn: Multi-model inference. R package version 1.9.13. http://CRAN.Rproject.org/package=MuMIn (2013).

46. Hill, S.L., Phillips, A. \& Atkinson, A. Potential climate change effects on the habitat of Antarctic krill in the Weddell quadrant of the Southern Ocean. PLoS One 8 (8), e72246 (2013).

\section{Additional Information}

Correspondence and requests for materials should be sent to AA (aat@pml.ac.uk) and SH (sih@bas.ac.uk). 


\section{Author Contributions}

$\mathrm{AA}$ and $\mathrm{SH}$ contributed equally as first authors providing the initial concept and analysis. AA, VS, EP: concept and construction of KRILLBASE databases; AA, EP, VS, CR, VL, DS, GT: supply of data to KRILLBASE; LG; mapping; SH: statistical analyses; ALL: Input of ideas to the study and to the manuscript.

\section{Acknowledgements}

We thank all those who have supplied their data to KRILLBASE, especially Arthur Baker for help with logbooks from the 1920s and 1930s, and Roger Hewitt, Robin Ross, Langdon Quetin and So Kawaguchi for provision of data or scientific advice. Mark Jessopp, Helen Peat and Natalie Ensor helped with compiling and checking the databases, Gareth Marshall advised on SAM indices, Frances Perry helped with mapping, Dawn Ashby helped with the infographic figure and comments from George Watters and five anonymous reviewers improved the manuscript. SH was supported by Natural Environment Research Council (NERC) core funding to the BAS Ecosystems programme. AA and SS were funded through NERC' National Capability Modelling; Long-term Single Centre Science Programme, Climate Linked Atlantic Sector Science, grant number NE/R015953/1, Theme 1.3 - Biological Dynamics; and NERC and the Department for Environment, Food and Rural Affairs (DEFRA) Marine Ecosystems Research Program (NERC project numbers NE/L003066/1 and NE/L003279/1. DKS was supported by the U.S. National Science Foundation's Antarctic Organisms and Ecosystems Program (grant PLR 1440435).

\section{Competing Interests}

None. 
Table 1: Significant relationships among krill density, mean length, Southern Annular Mode and year.

\begin{tabular}{|c|c|c|c|c|c|c|c|c|}
\hline Model & Fixed effects model & $\mathrm{m} 1(P)$ & $\mathrm{m} 2(P)$ & m3 (P) & c & $\mathbf{N}$ & $\mathbf{R}^{2} \mathbf{m}$ & $\begin{array}{l}R^{2} \mathrm{c} \\
(\mathrm{AIC})\end{array}$ \\
\hline 1 & $\begin{array}{l}\text { DENSITY }= \\
\left(m 1^{\star} \text { YEAR }\right)+(m 2 * L A T) \\
+\left(m 3^{\star} Y E A R^{\star} L A T\right)+c\end{array}$ & $\begin{array}{l}-0.065 \\
(<0.001)\end{array}$ & $\begin{array}{l}-87.437 \\
(<0.01)\end{array}$ & $\begin{array}{c}0.044 \\
(<0.001)\end{array}$ & 131 & 290 & 0.08 & $\begin{array}{l}0.15 \\
(773)\end{array}$ \\
\hline 2 & LENGTH $=m 1 *$ YEAR $+c$ & $\begin{array}{c}0.173 \\
(<0.001)\end{array}$ & & & -305 & 146 & 0.04 & $\begin{array}{l}0.33 \\
(931)\end{array}$ \\
\hline 3 & $\begin{array}{l}\text { RECRUIT DENSITY = } \\
\text { m1*YEAR+c }\end{array}$ & $\begin{array}{c}-0.069 \\
(<0.001)\end{array}$ & & & 137 & 124 & 0.08 & $\begin{array}{l}0.10 \\
(426)\end{array}$ \\
\hline 4 & D.DENSITY $=m 1 * D . L E N G T H+c$ & $\begin{array}{l}-0.044 \\
(<0.001)\end{array}$ & & & 0.138 & 124 & 0.01 & $\begin{array}{l}0.01 \\
(283)\end{array}$ \\
\hline 5 & $\begin{array}{l}\text { D.DENSITY }= \\
(m 1 * \text { D.SAM })+(m 2 * \text { SHELF })+c\end{array}$ & $\begin{array}{l}-0.229 \\
(<0.001)\end{array}$ & $\begin{array}{c}0.577 \\
(<0.05)\end{array}$ & & -0.186 & 290 & 0.01 & $\begin{array}{l}0.02 \\
(768)\end{array}$ \\
\hline 6 & D.LENGTH $=m 1 *$ D.SAM $+c$ & $\begin{array}{l}2.197 \\
(<0.01)\end{array}$ & & & 0.093 & 146 & 0.03 & $\begin{array}{l}0.38 \\
(918)\end{array}$ \\
\hline 7 & $\begin{array}{l}\text { D.RECRUIT DENSITY = } \\
\text { m1*D.SAM }+c\end{array}$ & $\begin{array}{l}-0.352 \\
(<0.05)\end{array}$ & & & -0.024 & 115 & 0.01 & $\begin{array}{l}0.03 \\
(417)\end{array}$ \\
\hline
\end{tabular}

Linear mixed model results indicating significant time trends in $\log _{10}$-transformed standardised post-larval krill density, no. $\mathrm{m}^{-2}$ (model 1 ), mean length in $\mathrm{mm}(2)$, and $\log _{10}$-transformed recruit density, no. $\mathrm{m}^{-2}$ (3); covariance in length and density (4); and relationships between the Southern Annular Mode index and each of standardised krill density (5), mean length (6) and recruit density (7). The fixed effects are expressed in terms of the coefficients $m 1, m 2, m 3$ and c. $\mathrm{N}$ is the number of observations (these are plotted in Fig. 2). All models include random spatial unit effects. Models 2 and 6 also include random year effects. $R^{2}$ is the marginal pseudo- $R^{2}$ indicating variance explained by the fixed effects and $R^{2}{ }_{c}$ is the conditional pseudo$\mathrm{R}^{2}$ indicating variance explained by both fixed and random effects. AIC is the Akaike information criterion. Variables prefixed "D" were de-trended. LAT values 0 and 1 represent latitudes north and south of $60^{\circ} \mathrm{S}$ respectively and SHELF values 0 and 1 represent shelf ( $\leq 1000 \mathrm{~m}$ depth) and oceanic waters respectively. 
FIGURE 1

a
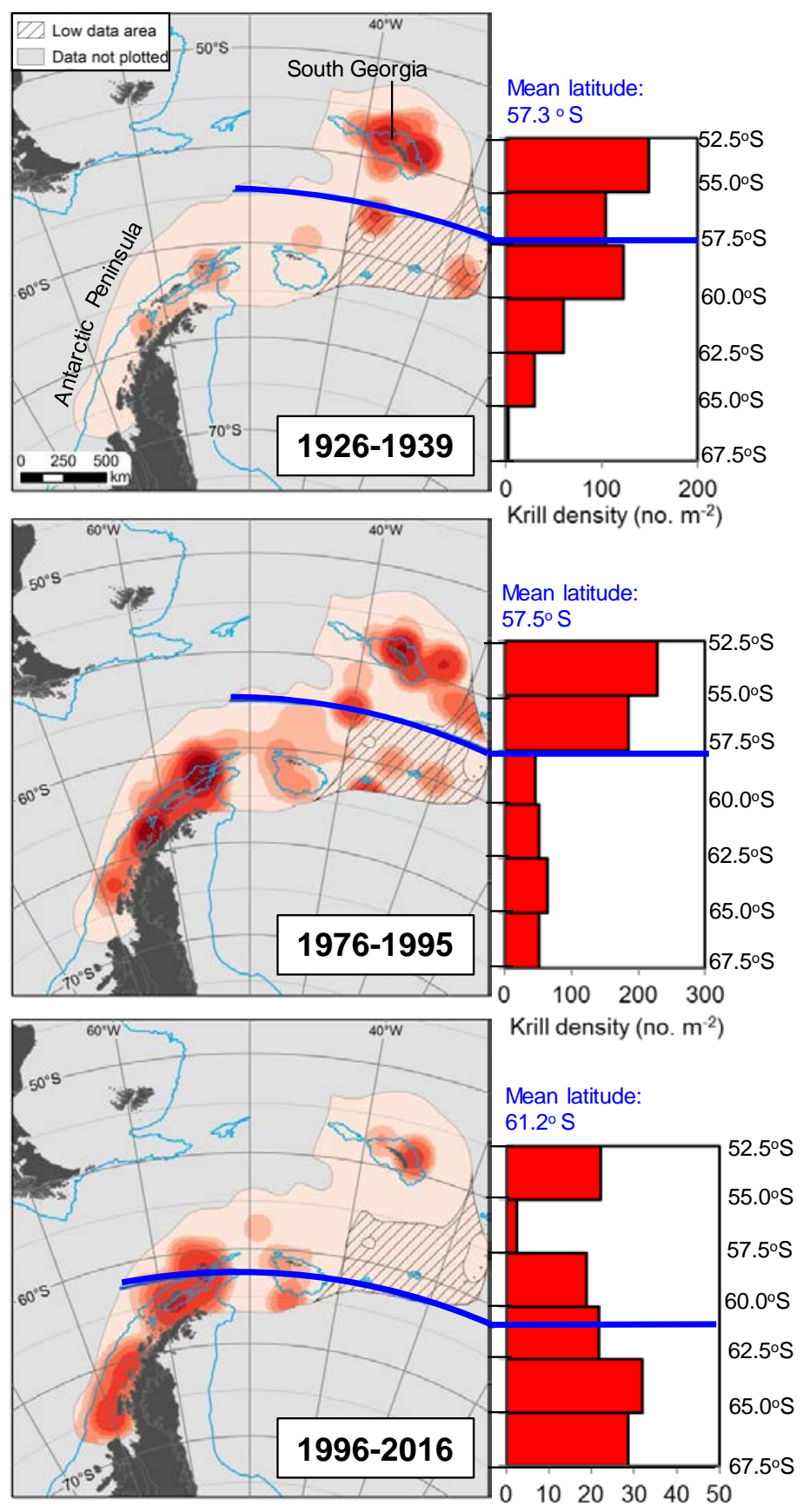

Krill density (no. $\mathrm{m}^{-2}$ ) b
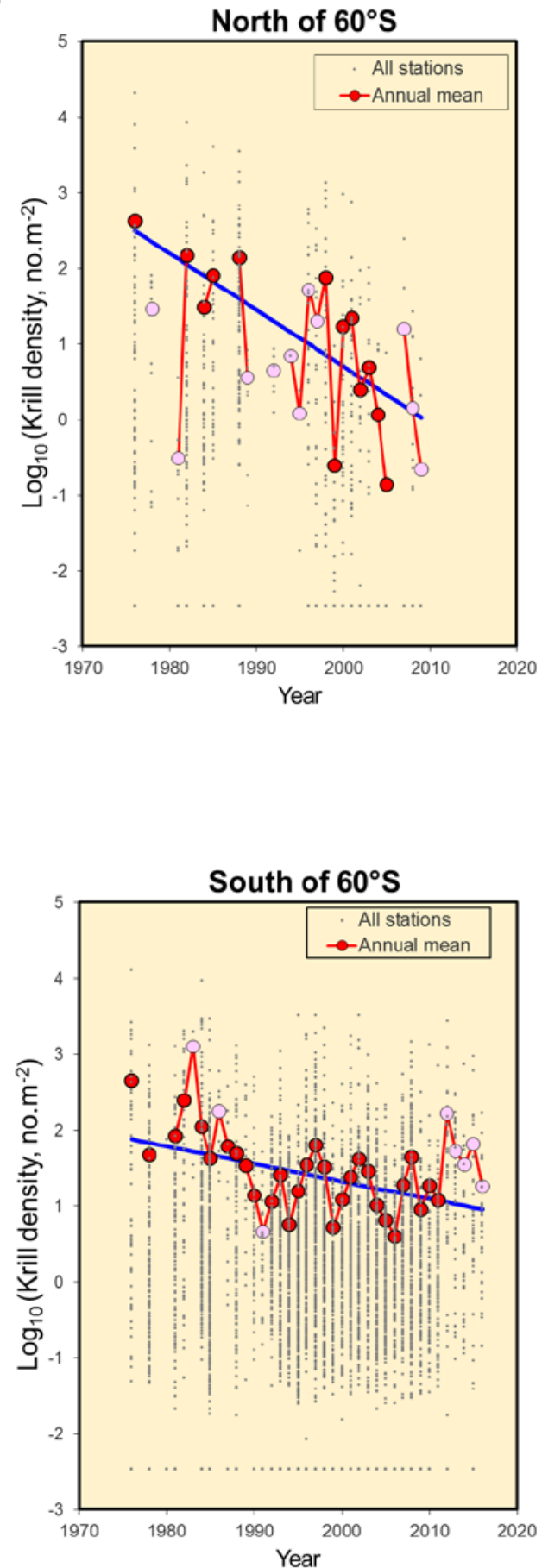


\section{Fig. 1: Southward contraction of krill distribution within the SW Atlantic sector.}

a Kernel analysis visualising hotspots of post-larval krill density in the SW Atlantic sector during the 1920s and 1930s and the first and second halves of the modern era, based on the area sampled heavily across all three periods (see Methods and Fig. S4). Blue isobaths denote the $1000 \mathrm{~m}$ boundary between shelf and oceanic habitats. Within each map, the analysis identifies relative hotspot areas of high density, indicated by intensity of red shading. The histograms denote the mean standardised post-larval krill density in six comparable $2.5^{0}$ latitude bands with > 50 stations sampled in each era (see Methods). Note changes in scale between each of the three eras. Thick blue lines across maps and histograms indicate the centre of krill density (i.e. density-weighted mean latitude; see Methods). b Trends in $\log _{10^{-}}$ transformed mean standardised post-larval krill density north and south of $60^{\circ} \mathrm{S}$. Small points represent the densities in underlying records, large dots represent the annual means of these data, weighted by the number of stations per record. Pink dots represent seasons with $<50$ stations (average 27 compared to an overall average of 123 stations per season). Solid blue trend lines were fitted to the annual means using simple linear regression $(P<0.001,<0.01$ adjusted $\mathrm{R}^{2}=0.52,0.22$ for North and South respectively). Linear mixed model no.1 in Table 1 and in Supplementary Table 1 provides statistical support for these trends and the significantly greater decline in the North. Fig. 2 provides finer latitudinal resolution, for instance showing an increase in density in the far south. 


\section{FIGURE 2}

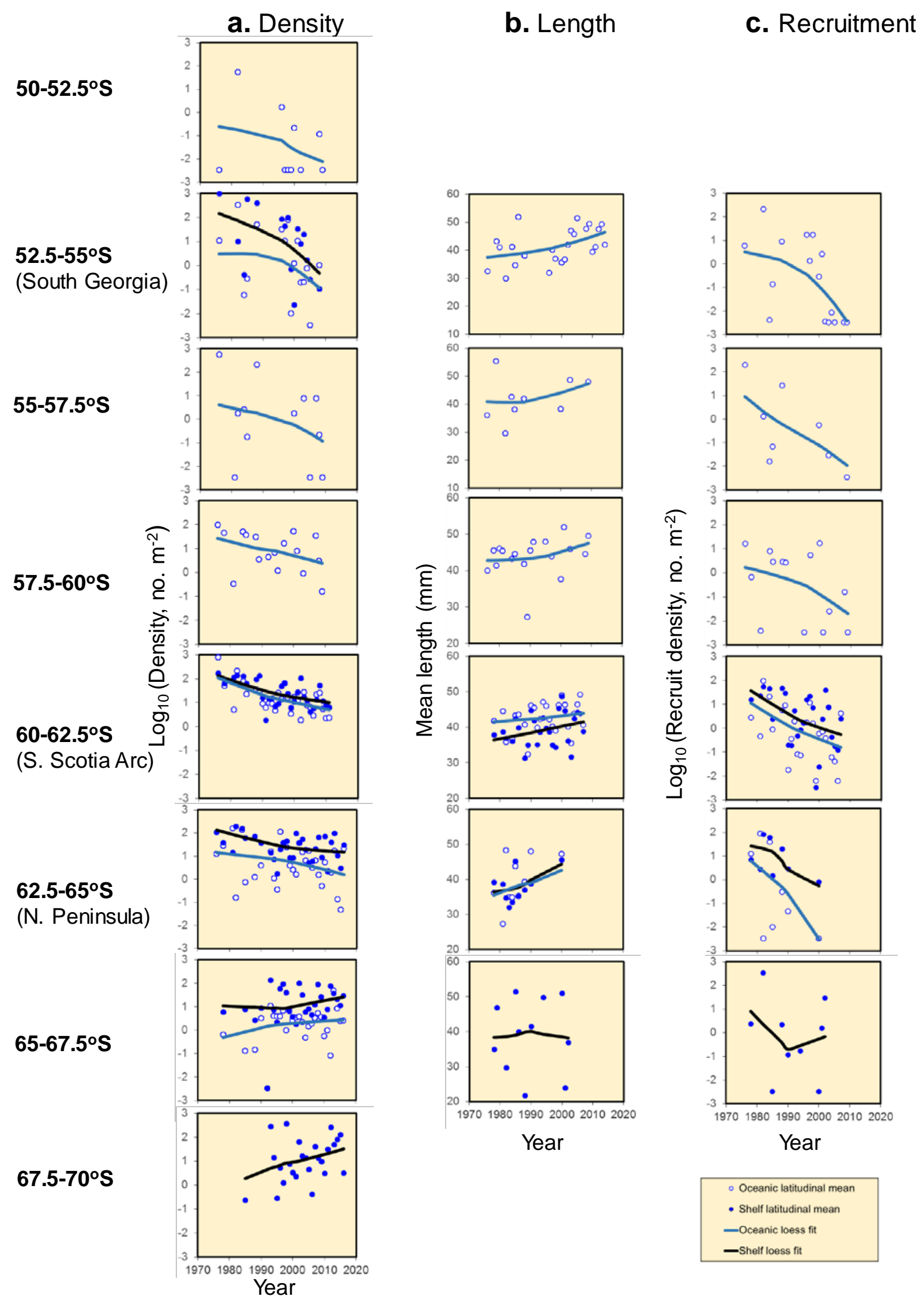


Fig. 2: A latitudinal gradation of change in krill dynamics over the last $\mathbf{4 0}$ years. The points are the spatio-temporal means that are included in the linear mixed model analysis in Table 1. These are grouped by latitude $\left(2.5^{\circ}\right.$ band) and bathymetry (shelf $\leq 1000 \mathrm{~m}$ water depth, versus oceanic waters). LOESS curves indicate trends within each spatial unit. The particularly well sampled bands at South Georgia and near the tip of the Antarctic Peninsula (Fig. S4) are labelled for reference. a Density of total post-larvae (i.e. new recruits plus older krill) from 7625 stations. Evidence for a range contraction is the sharp decline in density at the northern range fringes, with a progressive stabilisation and then reversal of the trends towards the south. b Data from 4308 length frequency sampling stations showing spatially-consistent increases in mean length. c Recruit density has declined very abruptly over the last 40 years in all areas except possibly for the far south. This is reflected both in the increase in mean length and the decline in density of total post-larvae. These trends appear broadly congruent across both shelf and oceanic habitats. 
FIGURE 3

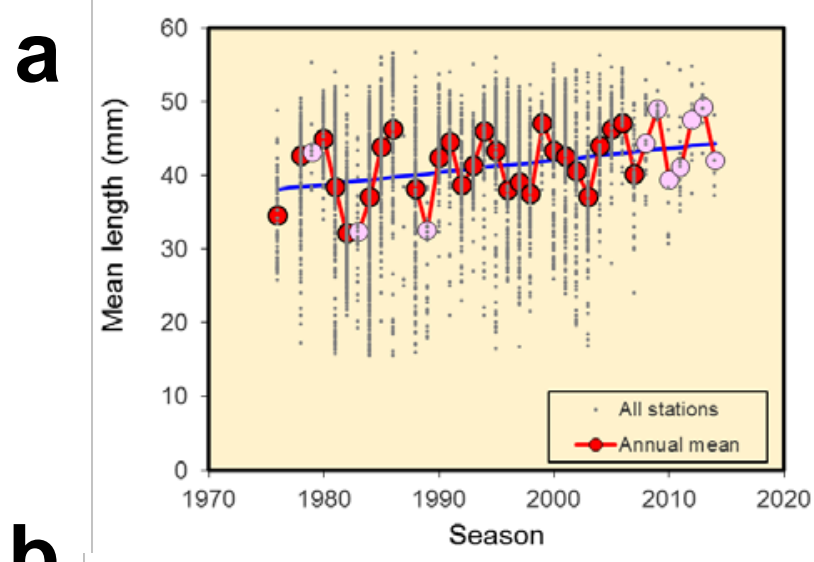

b
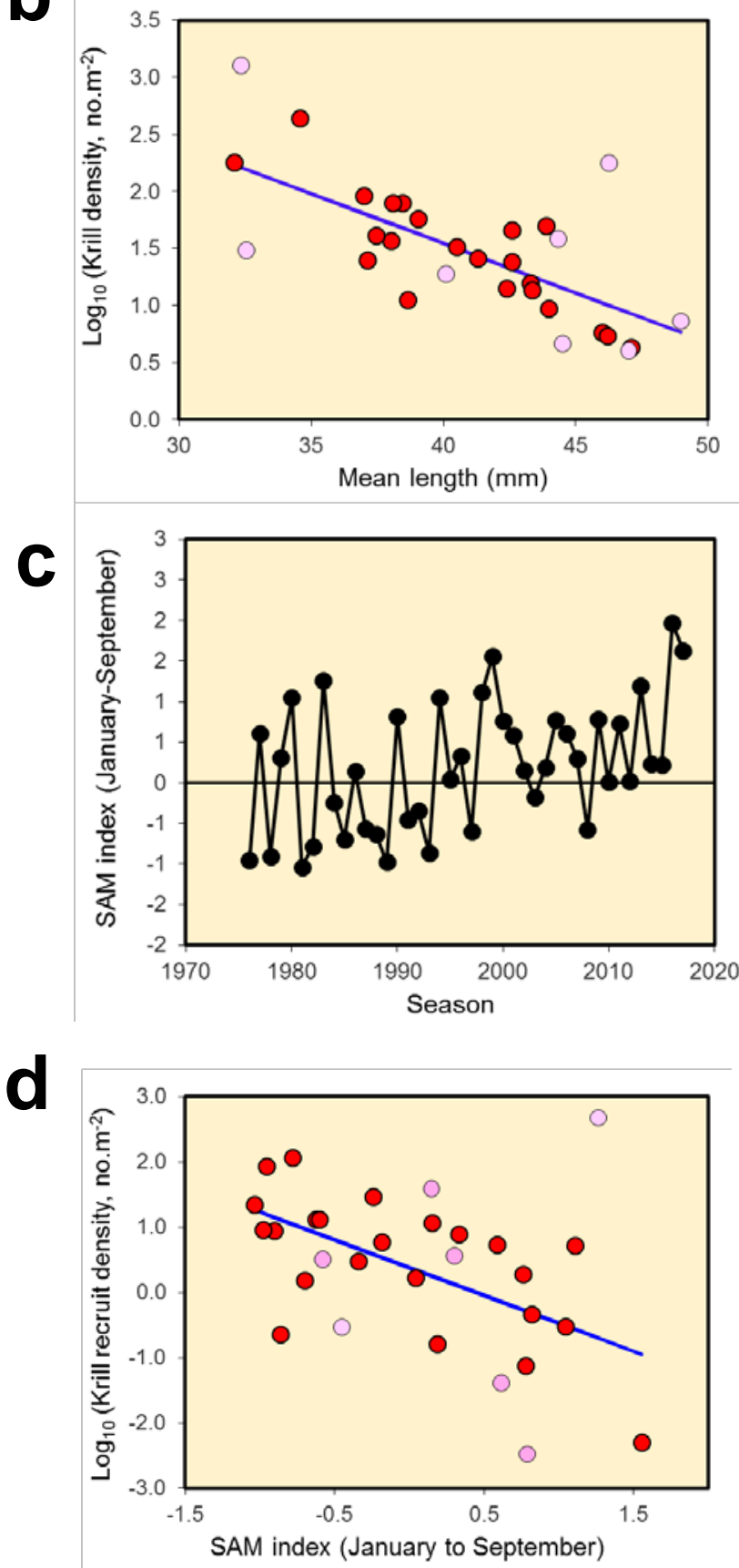
Fig. 3: Climatic forcing provides one mechanism for an increase in mean krill length and declines in recruitment and density. The linear mixed model results in Table 1, which include de-trending where appropriate, provide statistical support for the simple linear regression relationships illustrated here. a Increase in mean length of krill. Regression $P<0.05$, adjusted $R^{2}=0.09$; see mixed model no. 2 in Table 1. Small points represent the mean lengths in underlying records. Pink dots represent seasons with $<50$ stations (average 18 compared to an overall average of 116 stations per season). b Relationship between mean standardised post-larval krill density and mean length. Regression $P<0.001$, adjusted $R^{2}=0.47$; for detrended data see mixed model no. 4 in Table 1. c Inter-annual variation in January-September SAM anomaly during the modern era. Data are plotted with a 1-year lag, (i.e. Jan-Sept 2015 anomaly is plotted as 2016). d. Relationship between $\log _{10}$-transformed mean standardised recruit density (density of individuals $<30 \mathrm{~mm}$ long) and the SAM anomaly in the JanuarySeptember period preceding the krill sampling season. Regression $P<0.001$, adjusted $\mathrm{R}^{2}=0.30$. Mixed model nos. 5 to 7 in Table 1 provide relationships between krill and SAM. Pink dots represent seasons with $<50$ stations for either length or density. 


\section{Supplementary Figures \& Table}

Fig. S1: Recruit density has declined more rapidly than total post-larval density, which may be due to an increase in survival of older krill

Fig. S2: Ramifications of changing abundance, distribution and body size of krill.

Fig. S3: Tends in krill encounter probability by latitude suggest a decline in krill presence north of $60^{\circ} \mathrm{S}$.

Fig. S4: KRILLBASE-abundance coverage within the SW Atlantic sector showing coverage in each sampling period.

Fig. S5: KRILLBASE-length frequency coverage and trends in each sampling period.

Supplementary Table 1: Results of linear mixed models fitted to alternative datasets to assess sensitivity to data selection and standardisation of density data to a single net sampling method. 
a

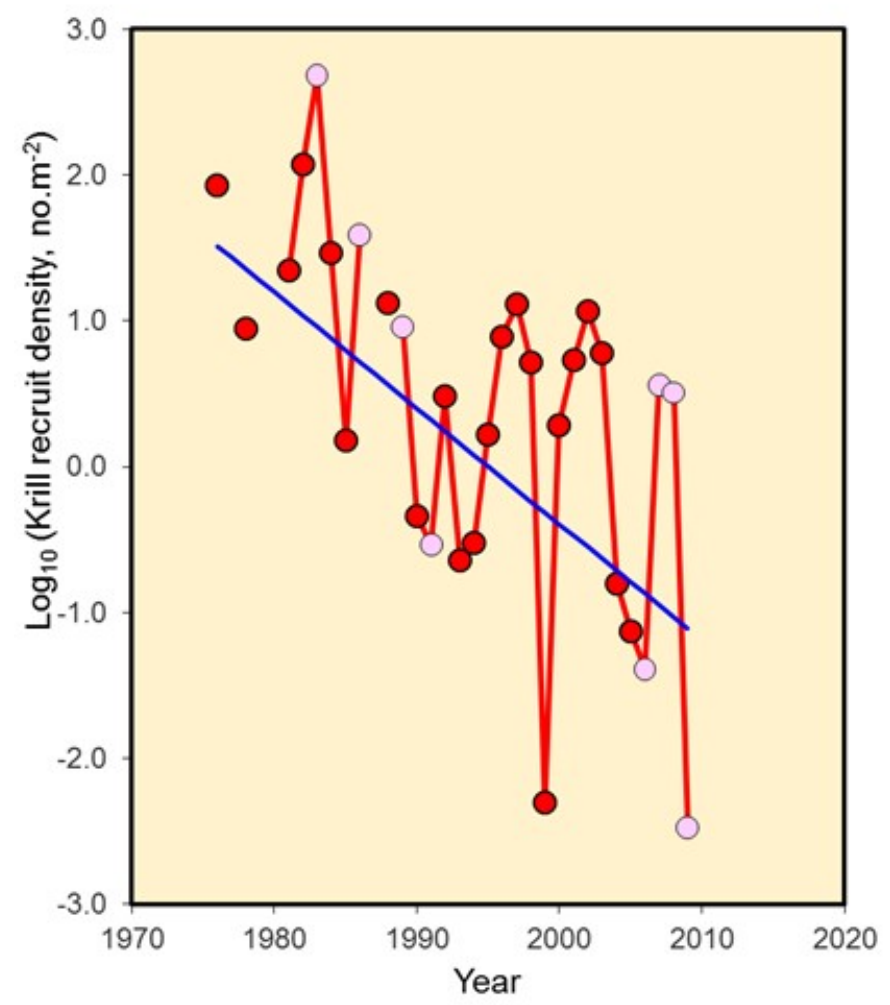

b

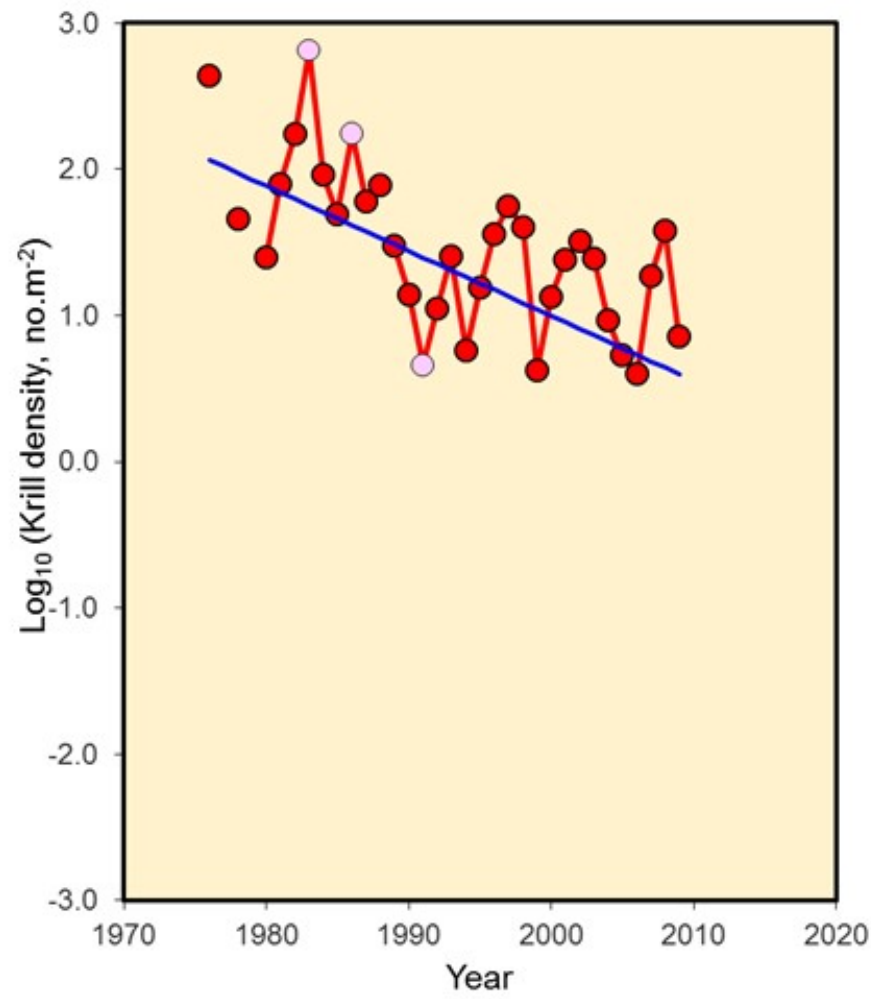

Fig. S1: Recruit density has declined more rapidly than total post-larval density, which may be due to an increase in survival of older krill. Linear mixed models of $\log _{10^{-}}$ transformed mean standardised recruit density and $\log _{10}$-transformed mean standardised post-larval krill density versus year confirm that the trend in the former $(-0.070)$ is significantly $(P<0.001)$ more negative than the trend in the latter $(-0.042)$ over the comparable joint measurement period. This difference is illustrated with simple linear regressions (blue lines) fitted to annual means of a recruit density $\left(P<0.001\right.$, adjusted $\left.R^{2}=0.39\right)$ and $\mathbf{b}$ total post-larval density $\left(P<0.001\right.$, adjusted $\left.\mathrm{R}^{2}=0.50\right)$. Pink dots represent seasons with $<50$ stations. 


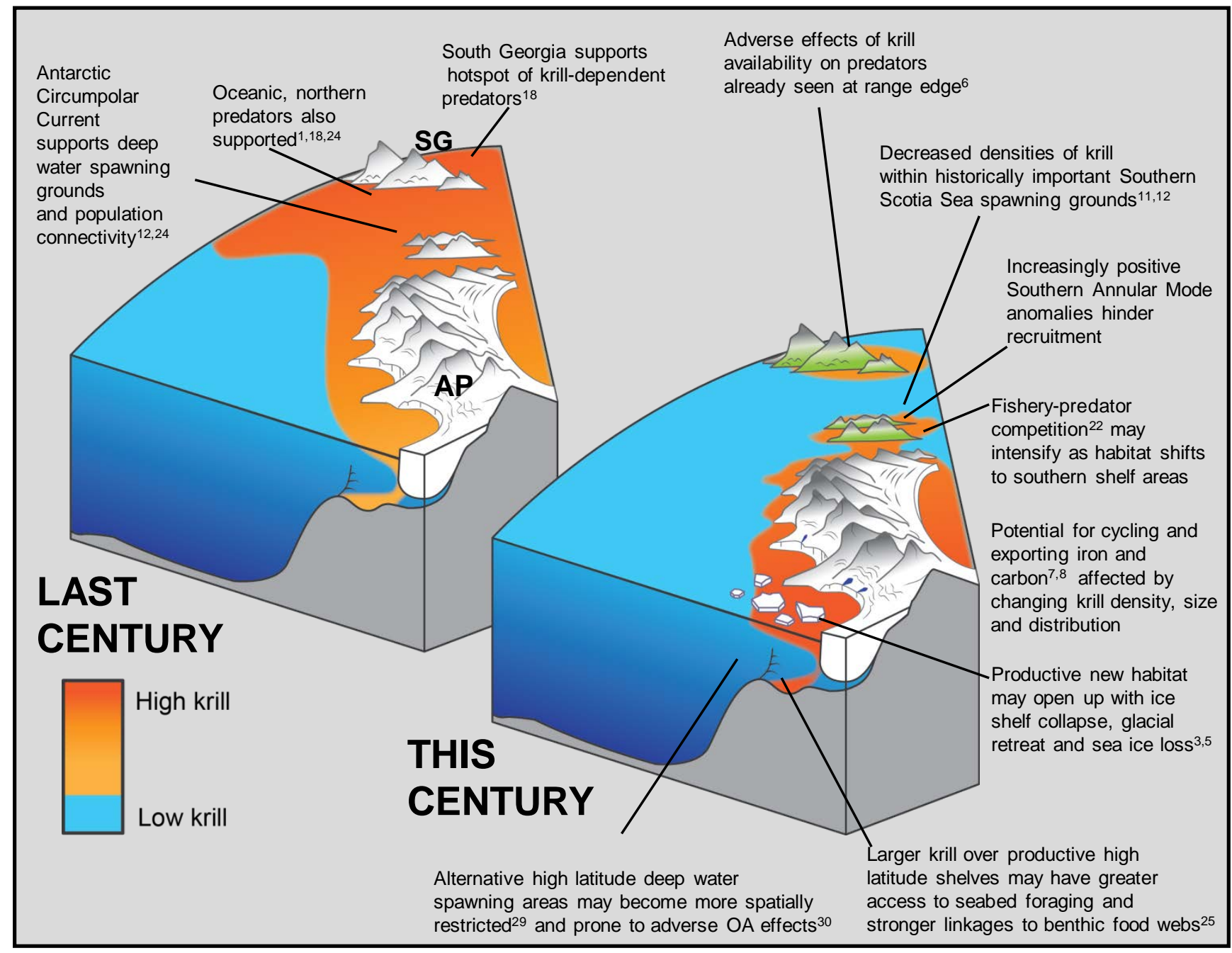

Fig. S2: Ramifications of changing abundance, distribution and body size of krill. The illustration portrays a view looking north-eastwards along the Antarctic Peninsula, AP towards South Georgia, SG (i.e. from bottom left corner of Fig. 1a), with the intensity of red shading showing changes in krill density and distribution that we have found. For reference, seasonal mean water temperatures at South Georgia have risen by $1.6^{\circ} \mathrm{C}$ over the last $\sim 80$ years ${ }^{13}$. We have summarised the potential implications of ongoing and future climate change this century (right hand panel) based on the observed changes and the projected increase in positive SAM anomalies for the next $\sim 50$ years $^{20}$. The schematic is not intended to be to scale but for reference is intended to span from $\sim 70^{\circ} \mathrm{S}$ to $\sim 50^{\circ} \mathrm{S}$; this represents roughly a doubling of maximum potential habitat areas between any pair of longitudes. OA means ocean acidification. 


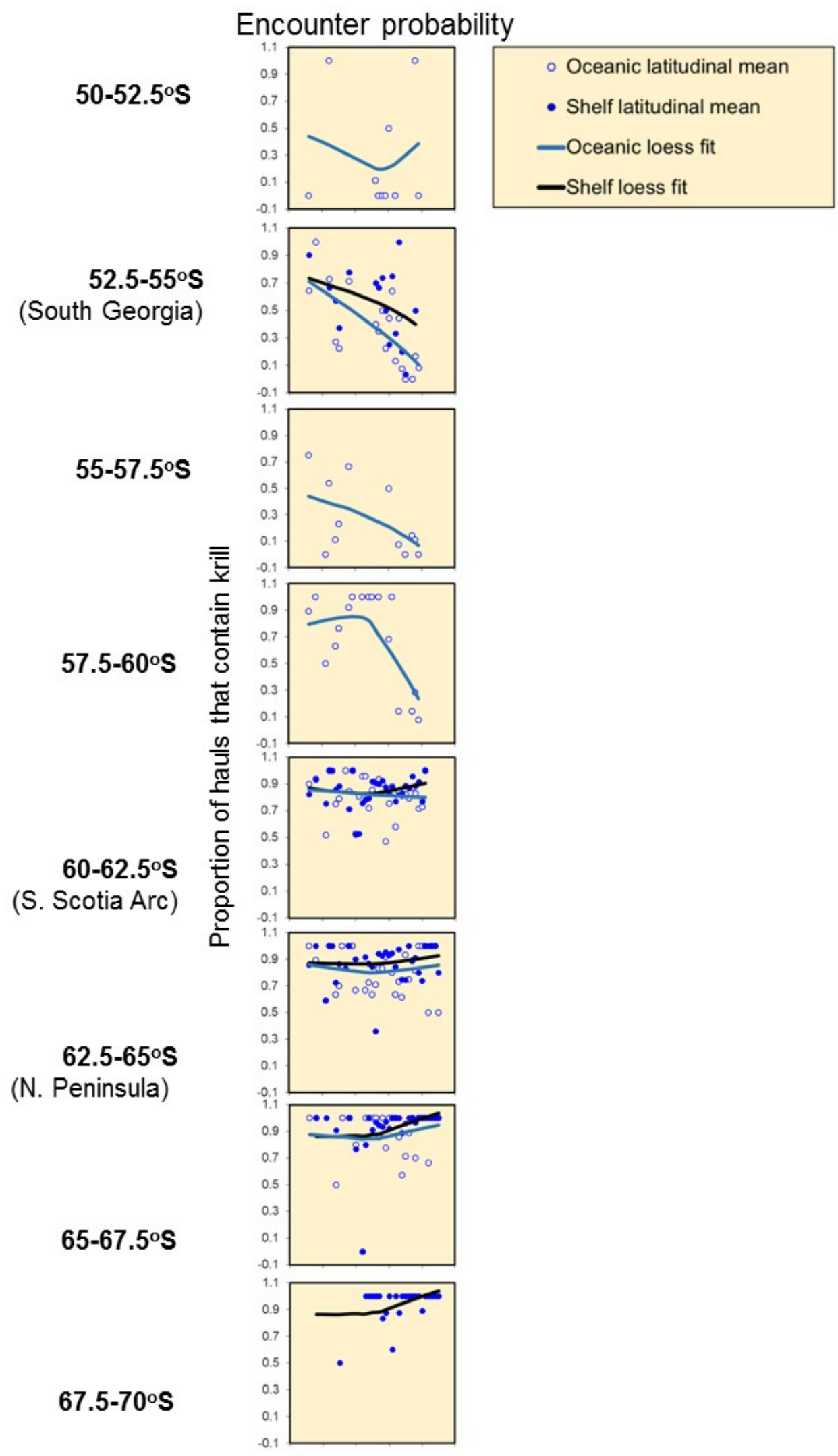

Fig. S3: Tends in krill encounter probability by latitude suggest a decline in krill presence north of $60^{\circ} \mathrm{S}$. Spatio-temporal means of encounter probability (proportion of hauls that contained krill), grouped by latitude $\left(2.5^{\circ}\right.$ band) and bathymetry (shelf $\leq 1000 \mathrm{~m}$ water depth, versus oceanic waters). LOESS curves indicate trends within each spatial unit. 
1926-1939

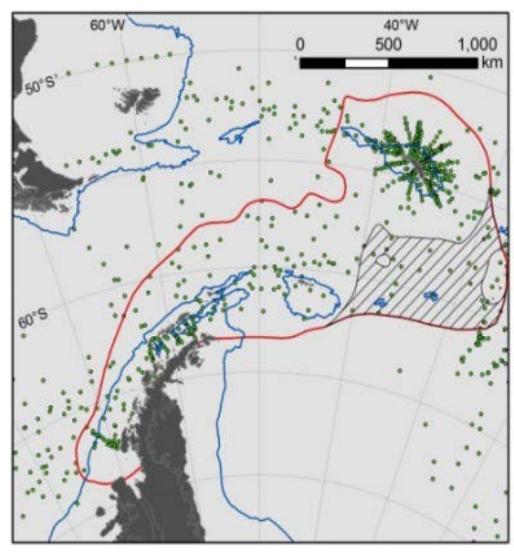

1976-1995

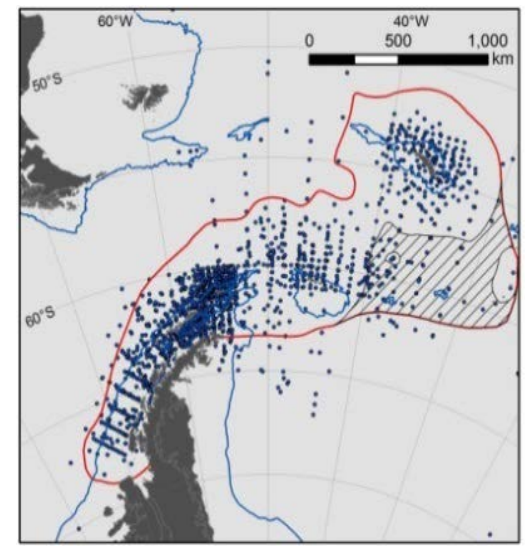

1996-2016

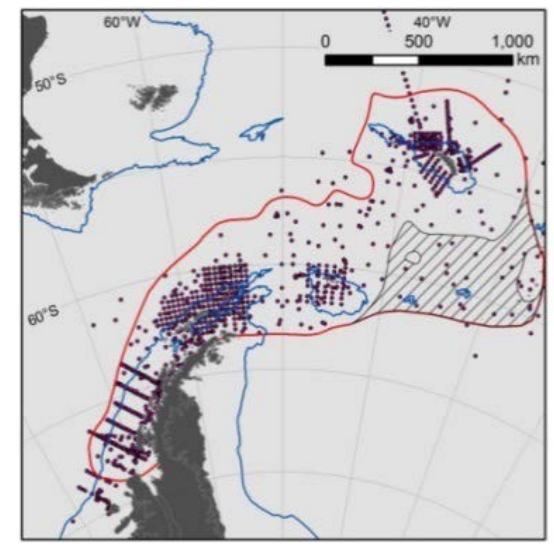

Fig. S4: KRILLBASE-abundance coverage within the SW Atlantic sector showing coverage in each sampling period. Points indicate sampling stations. The red line encloses the region with adequate sampling in all three periods, albeit with less consistent sampling density in the hatched area. This red-encircled area was selected for visualisation of density hotspots with kernel analysis. 
a
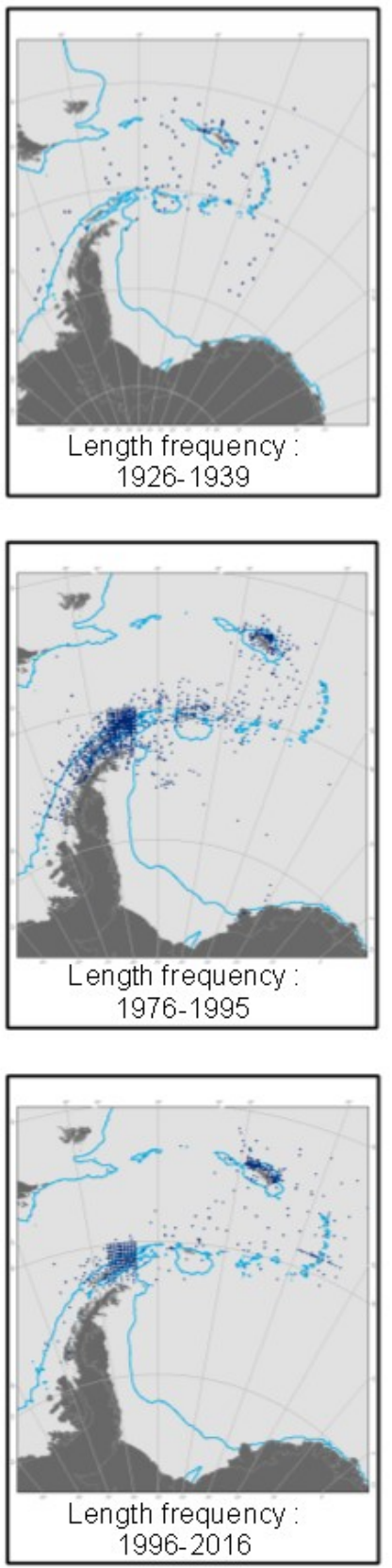

b
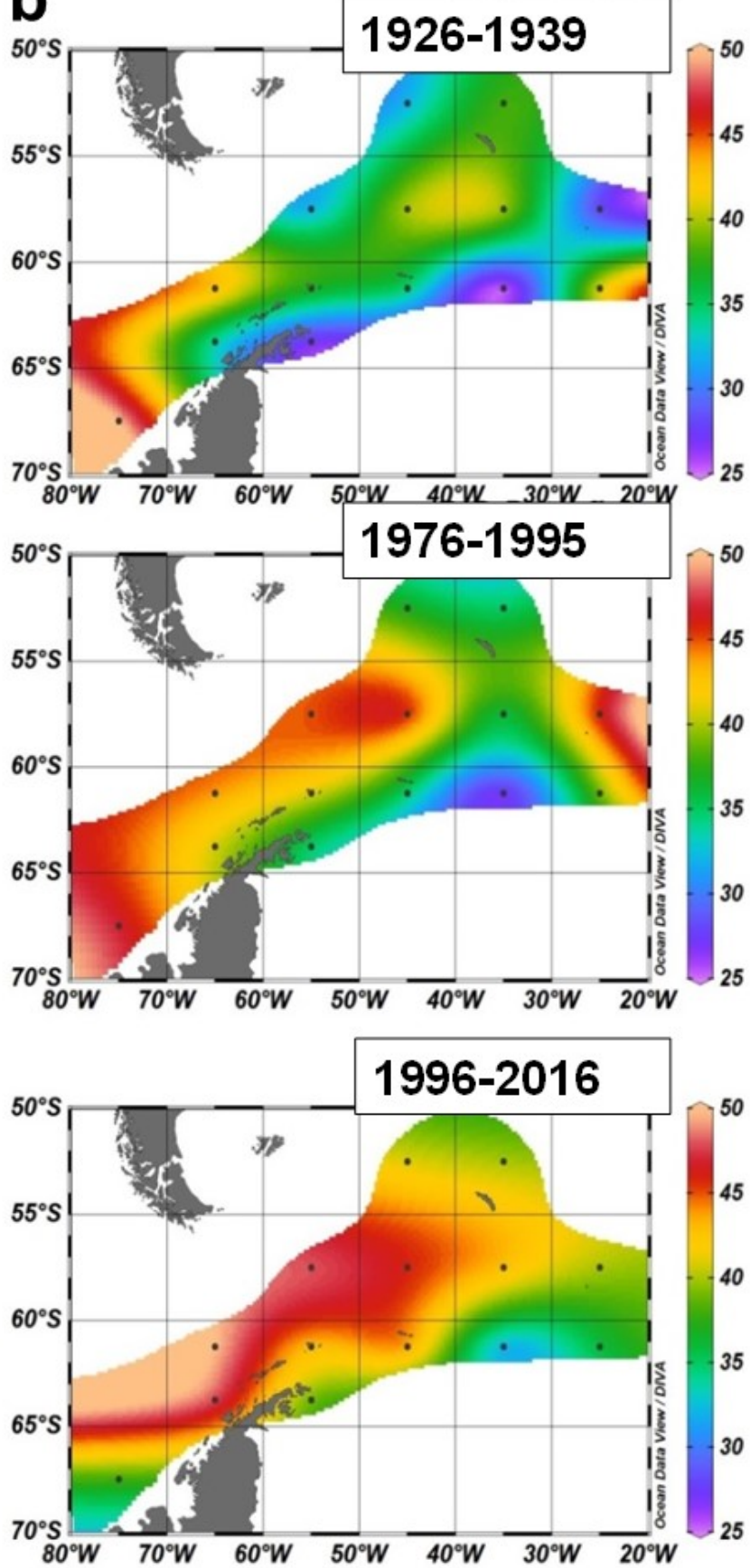

Fig. S5: KRILLBASE-length frequency coverage and trends in each sampling period. a

Sample coverage in each period; points indicate sampling stations. b For an initial visualisation of changes in mean length across the three eras we divided the SW Atlantic sector into a series of $5^{\circ}$ latitude by $10^{\circ}$ longitude grid cells. The region from $60-65^{\circ} \mathrm{S}$ was sampled more intensively than any other, enabling its further division into finer, $2.5^{\circ}$ latitudinal bands as done for the linear mixed models. Mean krill lengths within each grid cell within each era were then calculated. For an overview of changes in mean length across the three eras we used Ocean Data View (https://odv.awi.de/) visualisations of those grid cells which had data in all three periods. Most grid cells experienced an increase in mean length from the 1920s and 1930s through to the most recent sampling period. 
Supplementary Table 1: Results of linear mixed models fitted to alternative datasets to assess sensitivity to data selection and standardisation of density data to a single net sampling method.

\begin{tabular}{|c|c|c|c|c|c|c|c|c|}
\hline Model* & Summary & m1 (P) & $\mathrm{m} 2(P)$ & m3 $(P)$ & c & $\mathbf{N}$ & $\mathbf{R}_{\mathrm{m}}^{2}$ & $\begin{array}{c}R^{2}{ }_{c} \\
\text { (AIC) }\end{array}$ \\
\hline 1 & $\begin{array}{l}\text { Unstandardised } \\
\text { DENSITY } \\
\text { YEAR*LAT }\end{array}$ & $\begin{array}{c}-0.063 \\
(<0.001)\end{array}$ & $\begin{array}{l}-94.914 \\
(<0.01)\end{array}$ & $\begin{array}{c}0.048 \\
(<0.001)\end{array}$ & 127 & 290 & 0.07 & $\begin{array}{l}0.13 \\
(756)\end{array}$ \\
\hline 1 & $\begin{array}{l}\text { Standardised } \\
\text { DENSITY } \\
\text { YEAR*LAT } \\
(\text { where net } \\
\left.\text { mouth }<3 m^{2}\right) \\
\end{array}$ & $\begin{array}{c}-0.102 \\
(<0.001)\end{array}$ & $\begin{array}{c}-111.966 \\
\text { (NS) }\end{array}$ & $\begin{array}{l}0.057 \\
\text { (NS) }\end{array}$ & 204 & 60 & 0.18 & $\begin{array}{c}0.18 \\
(231)\end{array}$ \\
\hline 1 & \begin{tabular}{|l|} 
Standardised \\
DENSITY $\sim$ \\
YEAR*LAT \\
$($ where net \\
mouth $\geq 3 m^{2}$ ) \\
\end{tabular} & $\begin{array}{l}-0.034 \\
(<0.01)\end{array}$ & $\begin{array}{c}-30.178 \\
\text { (NS) }\end{array}$ & $\begin{array}{l}0.015 \\
\text { (NS) }\end{array}$ & 69 & 260 & 0.02 & $\begin{array}{l}0.08 \\
(640)\end{array}$ \\
\hline \multicolumn{9}{|c|}{ Models fitted to data with at least 15 stations per density estimate } \\
\hline 1 & \begin{tabular}{l|} 
Standardised \\
DENSITY \\
YEAR*LAT \\
\end{tabular} & $\begin{array}{c}-0.071 \\
(<0.001)\end{array}$ & $\begin{array}{l}-89.371 \\
(<0.05)\end{array}$ & $\begin{array}{c}0.045 \\
(<0.01)\end{array}$ & 144 & 144 & 0.01 & $\begin{array}{c}0.02 \\
(318)\end{array}$ \\
\hline 1 & $\begin{array}{l}\text { Unstandardised } \\
\text { DENSITY } \\
\text { YEAR*LAT }\end{array}$ & $\begin{array}{c}-0.065 \\
(<0.001)\end{array}$ & $\begin{array}{l}-90.036 \\
(<0.01)\end{array}$ & $\begin{array}{c}0.045 \\
(<0.01)\end{array}$ & 131 & 144 & 0.01 & $\begin{array}{c}0.01 \\
(312)\end{array}$ \\
\hline 1 & $\begin{array}{l}\text { Standardised } \\
\text { DENSITY } \\
\text { YEAR } \\
\text { (where net } \\
\text { mouth }<3 m^{2} \text { ) }\end{array}$ & $\begin{array}{c}-0.140 \\
(<0.01)\end{array}$ & & & 280 & 21 & 0.00 & $\begin{array}{l}0.00 \\
(84)\end{array}$ \\
\hline 1 & $\begin{array}{l}\text { Standardised } \\
\text { DENSITY } \\
\text { YEAR } \\
(\text { where net } \\
\text { mouth } \geq 3 \mathrm{~m}^{2} \text { ) } \\
\end{array}$ & $\begin{array}{l}-0.026 \\
(<001)\end{array}$ & & & 53 & 123 & 0.01 & $\begin{array}{c}0.03 \\
(238)\end{array}$ \\
\hline 3 & $\begin{array}{l}\text { RECRUIT } \\
\text { DENSITY } \\
\text { YEAR }\end{array}$ & $\begin{array}{c}-0.064 \\
(<0.001)\end{array}$ & & & 127 & 88 & 0.05 & $\begin{array}{l}0.05 \\
(286)\end{array}$ \\
\hline 4 & $\begin{array}{l}\text { D.DENSITY } \\
\text { D.LENGTH }\end{array}$ & $\begin{array}{c}-0.043 \\
(<0.001) \\
\end{array}$ & & & 0.209 & 88 & 0.00 & $\begin{array}{c}0.00 \\
(170) \\
\end{array}$ \\
\hline 5 & $\begin{array}{l}\text { D.DENSITY } \\
\text { D.SAM+SHELF }\end{array}$ & $\begin{array}{c}-0.236 \\
(<0.05) \\
\end{array}$ & 0.265 (NS) & & 0.226 & 144 & 0.00 & $\begin{array}{r}0.00 \\
(323) \\
\end{array}$ \\
\hline 7 & $\begin{array}{l}\text { D.R.DENSITY } \\
\sim \text { D.SAM } \\
\end{array}$ & $\begin{array}{l}-0.477 \\
(<0.05) \\
\end{array}$ & & & -0.284 & 88 & 0.01 & $\begin{array}{c}0.01 \\
(274) \\
\end{array}$ \\
\hline
\end{tabular}

* Number refers to the comparable model, fitted to all data, presented in Table 1. NS $=$ not significant $(P>0.05)$. Other details as Table 1. 